\title{
Study on sandstorm in the western section of Hexi Corridor of 2020
}

\author{
Haiyan Wang ${ }^{1, *}$, Qingming Tian ${ }^{1}$, and Caixia $\mathrm{Zhu}^{1}$ \\ ${ }^{1}$ Jiuquan Meteorological Bureau in Gansu Province, meteorological observatory, 39 Century Avenue in Jiuquan City,china
}

\begin{abstract}
A diagnostic analysis of the dust storm weather occurring in the western part of the Hexi Corridor from 27-30 June 2020 was carried out using Jiuquan city's live data, as well as ECMWF numerical forecasts, and the NCEP reanalysis information was used to draw a theta dust storm model based on the routing principle. The results show that: 1.In the early stage of sandstorm, there was no precipitation in Suzhou and Jinta counties in March and April, which resulted in dry surface and thickened soil layer. These factors created favorable conditions for the occurrence of dust weather. 2.Development of unstable trough eastward in front of the ridge of Mountain Ural at $500 \mathrm{hPa}$, The cold high pressure is continuously strengthened in the process of moving, which is the large-scale system leading to the sandstorm. Thermal depression in front of ground cold front is the main cause for the outbreak of the severe sandstorm. 3.The beginning and ending time of the sandstorm can be accurately predicted by the simulation chart of sandstorm forecast, which has a good indication significance for the sandstorm forecast in the Hexi area.
\end{abstract}

\section{Introduction}

Sandstorm is a disaster weather caused by the combination of special backgrounds on the large scale circulation and various different scale weather system that is more harmful and occurs mostly in arid and semi-arid areas ${ }^{[1]}$.For many years Chinese meteorologists analyze deeply the birthplace, transmission path and physical mechanism of sandstorm in China using a variety of datum and methods, and gain rather meaningful research outcomes. Such as Yuying Chen ${ }^{[2]}$ analyzed the meteorological influence factors on March 9,2013 in Ningxia. Li Qian ${ }^{[3]}$ carried out weather dynamics diagnostic analysis of the formation process and weakening reason of very strong sandstorm occurred on April 23,2014 in the Hexi Corridor in Gansu province. Ling $\mathrm{Li}^{[4]}$ analyzed the traits of strong sandstorm on March 19,2018 in the eastern of the Hexi Corridor.Mingrui Zhao ${ }^{[5]}$ carried out a study on the occurrence time and frequency of sandstorm in Gansu Minqin.Xiazhong. Caiyun Guo ${ }^{[6]}$ carried out a study on process and numerial simulation forecast of sandstorm in Taklimakan Desert Region. Xiaohong $\mathrm{Di}^{\left[{ }^{[7]}\right.}$ carried out comparative analysis of two strong sandstorms in Gansu province. Ablimitjan ABLIKIM ${ }^{[8]}$ carried out the analysis of east-blow sandstorm atmospheric boundary layer traits in Tarim Basin. The Hexi Corridor is one of the three areas where the sandstorm occurs mostly in China. In the western of the Hexi Corridor,sandstorm has become the most serious meteorological disaster in Spring and Summer. Especially the sandstorm occurs mostly from March to May in Spring ${ }^{[9]}$. However, the sandstorm occurred in Summer was different from other time,so it needs predictions in numerical models.
Umerical model is a power tool to simulate and forecast the sandstorm process and study sandstorm circulation and its effect. Since the end of the 1980s, many people have committed in to studying and developing models applying to simulate global,regional and local sandstorm processes ${ }^{[10]}$. There are global sandstorm transmission model, IAPS regional sandstorm process model,GRAPES-SDM sandstorm model, CAMET model and WRF/Chem model. Owing to the deviation of the understanding of physical process,there are uncertainty in many aspects of sandstorm numerical model, such as dust emission scheme,gravity dry settlement scheme,input data,numerical approximation and satellite remote sensing sandstorm index ${ }^{[11,12]}$. Shengqian Chen ${ }^{[13]}$ proposed that there is no study on the sandstorm change appearing different evolution model in arid and semi-arid areas in inland and whether different control factors in different areas are the same. Dunhuang city in the westernmost point of the Hexi area with three sides surrounded by the desert. Special local environment has certain effect on sandstorm model forecast. So this paper proposes to carry out numerial forecast simulation experiment of strong sandstorm in the western section of Hexi Corridor based on the principle of "Collapse theory" according to the special landform. We analyzed the vortical flows in vertical direction, potential tumble effect and the secondary vortical flows in horizontal direction the station to forecast the beginning and ending of the sandstorm and improve the precision of the model on sandstorm weather forecast by the V-30 structure from June 27,2020 to June 30,2020 in Guazhou station.

*Corresponding author: Haiyan Wang,1988- , mailbox:wang1012yan@126.com 


\section{Condition and Influence System}

\subsection{Pre-sandstorm climate}

The average temperature is $7.7^{\circ} \mathrm{C}$ from January 2020 to June 2020 in Jiuquan, $1.1^{\circ} \mathrm{C}$ higher than the same period of normal year,and is the highest in the past 7 years. The sandstorm caused rare drought in Winter and Spring. Compared with the same period of last year, the water quantity of shuangta reservoir, changma reservoir and yuanyangchi reservoir reduce by $29.4 \%, 14.7 \%$, $76.9 \%$, and the yuanyangchi reservoir is dry. The average amount of precipitation is $23.8 \mathrm{~mm}$ from January to June in Jiuquan, $28 \%$ lower than the same period of normal year, and is the lowest in the past 11 years. There are no precipitation in March and April in Suzhou and Jinta, which is rare in history. (Suzhou District has no precipitation in 1982 and 2020, and Jinta in 2009 and 2020,since the station was built.) According to analysis of the MODIS/Terra satellite data in June 2020,there are mild droughts in parts of Guazhou County, Yumen City, Akesai County, Dunhuang City, and Subei County, and moderate droughts in Suzhou District, Jinta County, and parts of Mazong Mountain. Because of drought, there is low soil moisture, dry surface and thickened soil. Jiuquan has more deserts,sparse vegetation and naked topsoil,which offers advantaged condition for sandstorm weather.

\subsection{Process Condition}

The sandstorm weather occurred from west to east at 13 pm on June 292020 in Jiuquan. By 19:30,Sandstorm weather occurred in Akesai County, Subei County, Dunhuang City, Guazhou County and Yumen City. Sandstorms occurred at Aksai Observation Station and Guazhou Observation Station, with minimum visibility of 600 meters and 552 meters respectively; Dunhuang City,Sandstorms occurred in parts of Yumen City and Subei County (Akesai County Station is under local management and there is no automatic regional station). The actual situation is as follows:

Table 1 The actual situation of sand and dust in Jiuquan City on June 29, 2020

\begin{tabular}{|c|c|c|c|}
\hline Place name & $\begin{array}{c}\text { Extreme } \\
\text { wind } \\
\text { speed } \\
(\mathrm{m} / \mathrm{s})\end{array}$ & $\begin{array}{c}\text { Minimum } \\
\text { visibility } \\
(\mathrm{m})\end{array}$ & $\begin{array}{c}\text { Start } \\
\text { Time }\end{array}$ \\
\hline $\begin{array}{c}\text { Yumen } \\
\text { City }\end{array}$ & 20.3 & 1411 & $19: 30$ \\
\hline $\begin{array}{c}\text { Guazhou } \\
\text { County }\end{array}$ & 23.5 & 552 & $17: 16$ \\
\hline $\begin{array}{c}\text { Dunhuang } \\
\text { City }\end{array}$ & 23 & 880 & $14: 30$ \\
\hline $\begin{array}{c}\text { Subei } \\
\text { County }\end{array}$ & 15.7 & 1010 & $16: 53$ \\
\hline $\begin{array}{c}\text { Akesai } \\
\text { County }\end{array}$ & 13.7 & 600 & $13: 00$ \\
\hline
\end{tabular}

\subsection{High Altitude Influence Weather System}

Late June before the sandstorm weather occurred,ural high pressure ridge devolopped and northerly jet strengthened in $500 \mathrm{hPa}$ altitude, which promoted the Bahu cold trough in the front deepened, and the front area strengthened. At 8:00 on June 29, the ural high pressure ridge continued to expand eastward, and its front $500 \mathrm{hPa}$ high-altitude cold trough front area reaches Urumqi. The cold center is located in Yining to Aksu and other places. The temperature difference between Aksu and Urumqi was $6{ }^{\circ} \mathrm{C}$, and the temperature difference with Dunhuang was $11^{\circ} \mathrm{C}$, and the Kuqa had $24 \mathrm{~m} / \mathrm{s}$ southerly wind. Westerly air currents greater than $14 \mathrm{~m} / \mathrm{s}$ controlled the central and western Hexi. At 8:00 on 29th, in $700 \mathrm{hPa}$ attitude, the low trough was splitting and moving eastward, but the speed of the movement was accelerating. The main force of cold air was located near Korla. The difference between Urumqi and Dunhuang was $6^{\circ} \mathrm{C}$. The low-level cold advection was strong. This circulation configuration was conducive to the strengthening of the ground system.Compared with very strong sandstorm on April 30,2014 in Jiuquan,sandstorm occurred at 9 earth stations in Jiuquan,among them,strong sandstorm occurred at 7 earth stations,very strong sandstorm occurred at Dunhuang and Akesai with 20-meter minimum visibility and $24.5 \mathrm{~m} / \mathrm{s}$ maximum instantaneous wind speed. At 08:00 on April $23,2014,500 \mathrm{hPa}$, the cold center was located in the area from Tacheng to Haba River, the center intensity was $-37^{\circ} \mathrm{C}$, and the temperature difference between Urumqi and Dunhuang was $18^{\circ} \mathrm{C}$. The main force of $700 \mathrm{hPa}$ cold air was located in the central and western part of northern Xinjiang. The temperature difference between Urumqi and Dunhuang was as much as $20^{\circ} \mathrm{C}$.

After comparison we can see that: In summer, the intensity of the cold advection of the sandstorm is weak. Based on past experience and with reference to numerical forecast products, without considering that there will be more than two stations with sandstorms weather in the Jiuquan, traditional synoptic analysis is not enough to forecast this summer sandstorm, because in fact there are three places with sandstorm in Jiuquan city.

\section{$3 \mathrm{~V}-3 \theta$ forecast simulation}

Figure V-3 $\theta$ is a kind of image structure designed by Shoucheng Ouyang ${ }^{[14-16]}$ to analyze and forecast the weather turning changes based on the principle of "Collapse theory". Conventional V-3 $\theta$ uses single-station sounding data to perform synoptic analysis on real sounding information.

\section{$3.13 \theta$ forecast}

We selected June 27 to forecast the $3 \theta$ forecast map of sandstorm in Guazhou on 29th. $3 \theta$ sandstorm simulation forecast map coverred the datum of the trait layer, prescribed layer from ground to advection layer including ultra-low temperature information, among 
them, from left to right are $\theta, \theta_{\mathrm{se}}, \theta^{*}$.

At 5:00 on the 29 th(a), $\theta, \theta_{\text {se }}$ and $\theta^{*}$ tilted to the right with $\mathrm{P}$ at $300 \mathrm{hpa}$, which showed atmospheric vertical structure above $300 \mathrm{hpa}$ is homogenizatial. The three lines $\theta$, $\theta$ se and $\theta^{*}$ below 300hpa had only one turn around 500hpa which showed that there were some medium-high clouds at an altitude of 5500 meters;(b) at 11:00 on the 29 th, near the ground to $700 \mathrm{hpa} \theta_{\text {se }}$, tilted to the left with $\mathrm{P}$ which showed that the vertical structure of the lower and middle layers of the atmosphere is not homogenizatial. There was a phenomenon of "ultra-low temperature" ,which showed that intense weather was about to appear. It was easy to ignore this phenomenon when doing traditional weather analysis. When $\theta_{\mathrm{se}}-\theta=10$ $\mathrm{K}$, sandstorm weather was coming;(c)At 15:00 on the 29th,near the ground to 500hpa, $\theta$ gradually paralleled with $P, \theta$ was close to $\theta_{\mathrm{se}}$, and the left tilted rate of $\theta^{*}$ was greater. When $\theta_{\mathrm{se}}-\theta=5 \mathrm{~K}, \theta_{*}-\theta_{\mathrm{se}}=140 \mathrm{~K}$, tumble occurred, which showed at this moment there would be sandstorms or had already appeared. The occurrence time of sandstorm predicted by this $3 \theta$ sandstorm simulation forecast map was consistent with the actual occurrence time;(d) At 23:00 on the 29th,near the ground to 400hpa, the interval between $\theta$ and $\theta_{\text {se }}$ was larger than (c), and $\theta_{\text {se }}$ was between $\theta$ and $\theta^{*}$, comparing the previous few times, it could be shown that the stratification humidity increased at 23 o'clock, and the counter-tumble flow occurred, indicating the end of the sandstorm.

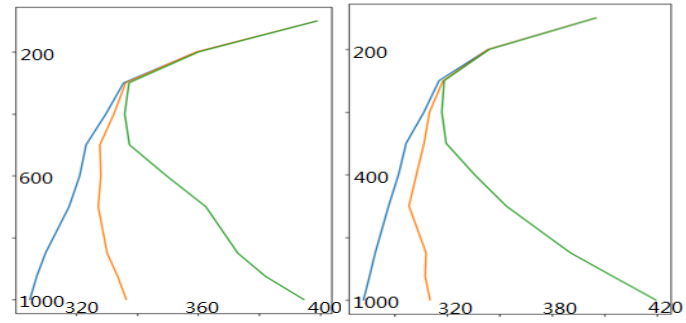

$$
\text { (a) } 29^{\text {th }} 05: 00
$$

(b) $29^{\text {th }} 11: 00$

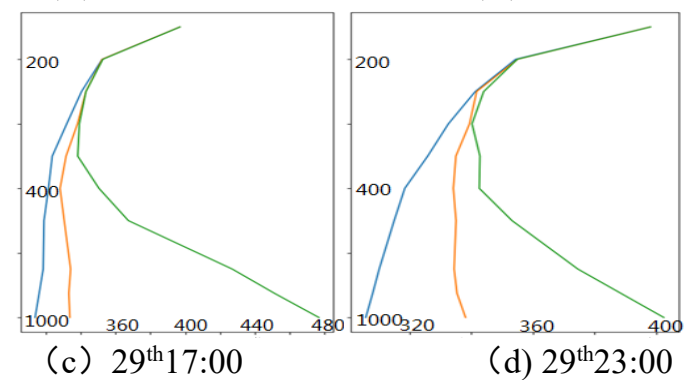

Figure 1 The forecast on June 27 and the $3 \theta$ forecast map of Guazhou County on June 29

\subsection{Physical quantities forecast}

We selected June 28 to forecast the vertical velocity and specific humidity forecast map,and blue was specific humidity curve, yellow was vertical speed curve. The map covered the change condition from near the ground to advection layer of specific humidity and vertical velocity of Guazhou. Figures (a) and (b) As the height increases, the specific humidity decreased, and the lower air had a higher water vapor content in the higher air;Figure (c) From near the ground to $700 \mathrm{hPa}$, as the height rose, the vertical speed decreased, and both were negative speeds. As the height rose from $700 \mathrm{hPa}$ to $500 \mathrm{hPa}$, the vertical speed increased, and the lower layer was negative speed, and the upper layer was positive speed. The rate of speed change was the largest, which coincided with the eruption time of the sandstorm;Figure (d) From near the ground to $700 \mathrm{hPa}$, as the height rose, the vertical speed increased, and both were negative speeds. Compared with the lower layer of Figure (c), the vertical speed changed at the opposite rate. As the height rose from $700 \mathrm{hPa}$ to $500 \mathrm{hPa}$, the vertical speed increased. If the speed comparison chart (c) was the same as the height, the speed comparison chart (c) was smaller, indicating that the wind speed in Guazhou County would decrease and the sandstorm would end.

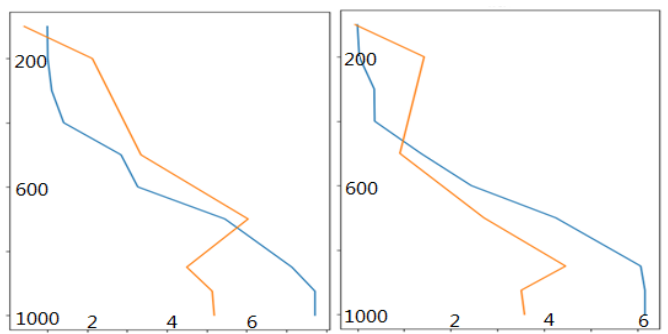

(a) 29th05:00

(b) 29th11:00

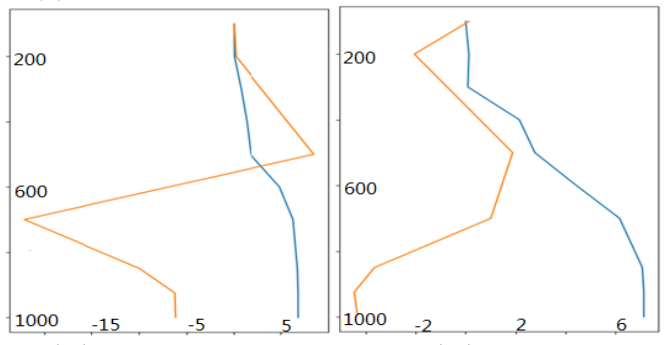

(c) 29th17:00

(d) $29 \operatorname{th} 23: 00$

Figure 2 The forecast of vertical velocity and specific humidity in Guazhou County on June 28 and June 29

\section{Conclusion}

(1) In the early days of the sandstorm, Suzhou and Jinta had no precipitation in March and April, and the dry surface soil layer was thickened, which created advantaged conditions for the occurrence of sandstorms.

(2) The unstable trough in front of the $500 \mathrm{hPa}$ Ural high pressure ridge moved eastward, and the cold high pressure continued to strengthen during the movement. It was a large-scale trigger system generated by this sandstorm. The strong wind brought by the hot low pressure in front of the ground cold front was the main reason of the occurrence of sandstorms.

(3) The $3 \theta$ forecast in the V- $3 \theta$ sandstorm simulation predicted vortical flows in the vertical direction and "ultra-low temperature" phenomenon in Guazhou County in advance. Figure V-3 $\theta$ accurately predicting the beginning time and end timeof the sandstorm were very indicative for the forecast of sandstorms in the Hexi area. 


\section{References}

1.Shigong Wang, Guangrong Dong, Huizhong Chen, Xiliang Li, Jiong Jin, Journal of Desert Research 4, 5-12 (2000).

2.Yu-ying Chen, Nan Chen, Zhi-qiang Tan, Qiang Li, Jing-xin Nie, Arid Land Geography 39, 285-293 (2016)

3.Li Qian, Jie Teng, Jingge Hu, Meteorological Monthly 41,745-754 (2015),

4.Lingping Li, Yanying Li, Weicheng Liu, Desert and Oasis Meteorology 14,10-17 (2020)

5.Mingrui Zhao, Xiaoling Yang, Shuichang Teng, Journal of Arid Meteorology 30,421-425+436 (2012)

6.Caiyun Guo, Zhiwen Han, Aimin Lo, Journal of Desert Research 36,1646-1652 (2016)

7.Xiaohong Di, Xinrong Zhang, Xinwei Liu, Honge Sha, Journal of Arid Meteorology 32,81-86 (2014)

8.Ablimitjan ABLIKIM, Na Li, Keming Zhao, Mingjing Sun, Yue Min, Desert and Oasis Meteorology 13,55-61 (2019)

9.Zhen-an Qian, Minghong Song, Wanyuan Li, Journal of Desert Research 2,10-15 (2002)

10.Chenglai $\mathrm{Wu}$, Zhaohui Lin, Climatic and Environmental Research 19,419-436 (201)

11.Haixia Duan, Ni Guo, Wen Huo, He Qin, Yufen Ma, Journal of Desert Research 34,1617-1623 (2014)

12.Jie Zheng, Zifa Wang, Jiang Zhu, Jie Li,FANG F,PAIN C C, Climatic and Environmental Research 21,663-677 (2016)

13.Shengqian Chen, Jianbao Liu, Jianwei Chen, Fahu Chen,Scientia Sinica(Terrae) 50,1316-1318 (2020)

14.Shoucheng Ouyang, Na Xie, Liping Hao, Strategic Study of CAE 09, 9-13 (2005)

15.Shoucheng Ouyang, Kui Zhang, Liping Hao, Lirong Zhao, Strategic Study of CAE 04, 36-41. (2005)

16.Shoucheng Ouyang, Dongsheng Yuan, Qin Zhong, Journal of Chengdu University of Information Technology 03, 111-117 (1996) 